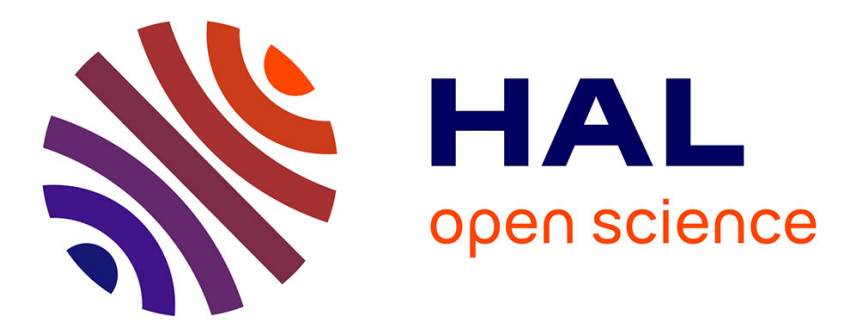

\title{
Charge Effect on the Formation of Polyoxometalate-Based Supramolecular Polygons Driven by Metal Coordination
}

Madeleine Piot, Sébastien Hupin, Hélène Lavanant, Carlos Afonso, Laurent Bouteiller, Anna Proust, Guillaume Izzet

\section{To cite this version:}

Madeleine Piot, Sébastien Hupin, Hélène Lavanant, Carlos Afonso, Laurent Bouteiller, et al.. Charge Effect on the Formation of Polyoxometalate-Based Supramolecular Polygons Driven by Metal Coordination. Inorganic Chemistry, 2017, 56 (14), pp.8490-8496. 10.1021/acs.inorgchem.7b01187 . hal01565261

\section{HAL Id: hal-01565261 \\ https: / hal.sorbonne-universite.fr/hal-01565261}

Submitted on 19 Jul 2017

HAL is a multi-disciplinary open access archive for the deposit and dissemination of scientific research documents, whether they are published or not. The documents may come from teaching and research institutions in France or abroad, or from public or private research centers.
L'archive ouverte pluridisciplinaire HAL, est destinée au dépôt et à la diffusion de documents scientifiques de niveau recherche, publiés ou non, émanant des établissements d'enseignement et de recherche français ou étrangers, des laboratoires publics ou privés. 


\title{
Charge effect on the formation of polyoxometalate-based supramolecular polygons driven by metal coordination
}

Madeleine Piot, ${ }^{[a]}$ Sébastien Hupin, ${ }^{[b]}$ Hélène Lavanant, ${ }^{[b]}$ Carlos Afonso, ${ }^{[b]}$ Laurent Bouteiller, ${ }^{[\mathrm{a}]}$ Anna Proust, ${ }^{[\mathrm{a}]}$ Guillaume Izzet $^{[\mathrm{a}] *}$

[a] M. Piot, Dr. L. Bouteiller, Prof. A Proust, Dr. G. Izzet, Institut Parisien de Chimie Moléculaire, CNRS UMR 8232 Sorbonne Universités, UPMC-Paris06, 4 Place Jussieu, F75005 Paris, France, E-mail: guillaume.izzet@upmc.fr

[b] S. Hupin, Dr. H. Lavanant, Prof. C. Afonso, Normandie Univ, UNIROUEN, INSA Rouen, CNRS, COBRA, 76000 Rouen, France

\begin{abstract}
The metal driven self-assembly of a Keggin-based hybrid bearing two remote pyridine units was investigated. The resulting supramolecular species were identified by combination of 2D diffusion NMR spectroscopy (DOSY) and electrospray ionization mass spectrometry (ESI-MS) as a mixture of molecular triangles and squares. This behaviour is different to that of the structural analogue Dawson-based hybrid displaying a higher charge, which only led to the formation of molecular triangles. This study highlights the decisive effect of the charge of the POMs in their self-assembly processes that disfavours the formation of large assemblies. An isothermal titration calorimetry (ITC) experiment confirmed the stronger binding in the case of the Keggin hybrids. A correlation between the diffusion coefficient $D$ and the molecular mass $M$ of the POM-based building block and its coordination oligomers was also observed. We show that the diffusion coefficient of these compounds is mainly determined by their occupied volume rather than by their shape.
\end{abstract}

\section{Introduction}

Self-assembly is an attractive approach to elaborate complex nanostructured molecular architectures. Starting from molecular-sized building blocks of known topologies, 0D to 3D supramolecular systems can be built in a straightforward manner. Among the various synthetic approaches, metal-driven self-assembly is a powerful route for controlling the topology of the desired molecular architectures by using suitable metallic ions and ligands. ${ }^{1-6}$ Polyoxometalates (POMs) are anionic oxo-clusters of high oxidation-state transition metal 
ions whose remarkable electronic properties are suitable for various technological applications. ${ }^{7,8}$ Owing to their nanoscale size, their structural complexity and their sensitivity to various types of interactions, ${ }^{9}$ POMs are attractive molecular building-blocks for the elaboration of supramolecular architectures with emergent ${ }^{10-13}$ or synergistic properties such as molecular separation, ${ }^{14}$ self-healing, ${ }^{15}$ luminescence, ${ }^{16,17}$ or crystal morphogenesis. ${ }^{18}$ Their functionalization into covalent organic-inorganic hybrids is a first step toward their integration into more complex assemblies. In this context, we recently described the selfassembly of covalent POM-based hybrids through metal coordination. ${ }^{19}, 20$ The hybrids developed in these studies were organosilyl functionalized Dawson-type POMs bearing remote binding sites (pyridine or terpyridine units). These hybrids display two organic arms approximately perpendicularly oriented, ${ }^{21-23}$ a topology that is well suited for elaborating molecular polygons by coordination to a metal linker. Furthermore, when using a cationic linker, the discrete supramolecular assembly could further self-assemble through intermolecular electrostatic interactions into an unprecedented multiscale organized system according to the solvent composition. ${ }^{19}$ The discrete molecular polygons were identified as supramolecular triangles, while molecular squares were expected owing to the $c a .90^{\circ}$ angle between the pendant arms of the starting hybrid. This suggests that the charge of the POM plays a major role in the formation of the cyclic assembly. Indeed, the formation of highly charged supramolecular species has potentially an important entropic cost due to the confinement of the associated counter-ions.

Organo-silyl derivatives of monovacant POMs can be also prepared in the Keggin series. Interestingly these Keggin (i.e. $\left[\mathrm{PW}_{11} \mathrm{O}_{39}\left\{\mathrm{O}(\mathrm{SiR})_{2}\right\}\right]^{3-}$ ) and Dawson (i.e. $\left.\left[\mathrm{P}_{2} \mathrm{~W}_{17} \mathrm{O}_{61}\left\{\mathrm{O}(\mathrm{SiR})_{2}\right\}\right]^{6-}\right)$-based hybrids display a very similar topology with approximately orthogonal organic arms but distinct charge. ${ }^{24}$ This drove us to evaluate the effect of the charge of the molecular building block on the structure of the resulting self-assembly. We herein report the metal-directed self-assembly of a Keggin-based molecular building block. We show that the resulting supramolecular structures are a mixture of molecular triangles and squares. This study outlines the major role of the charge of the POMs in their self-assembly.

\section{Results and Discussion}

\section{Formation of mixtures of molecular triangles and squares}


The Keggin-type pyridyl-terminated POM-based building block $\mathrm{TBA}_{3}\left[\mathrm{PW}_{11} \mathrm{O}_{39}\{\mathrm{O}(\mathrm{Si}\right.$ $\mathrm{C}_{13} \mathrm{H}_{8} \mathrm{~N}$ ) 2 \}], denoted as $\mathbf{K}$ si[pyr $]^{25}$ (Figure 1) was synthesized according to a previously reported synthetic procedure. ${ }^{26,27}$

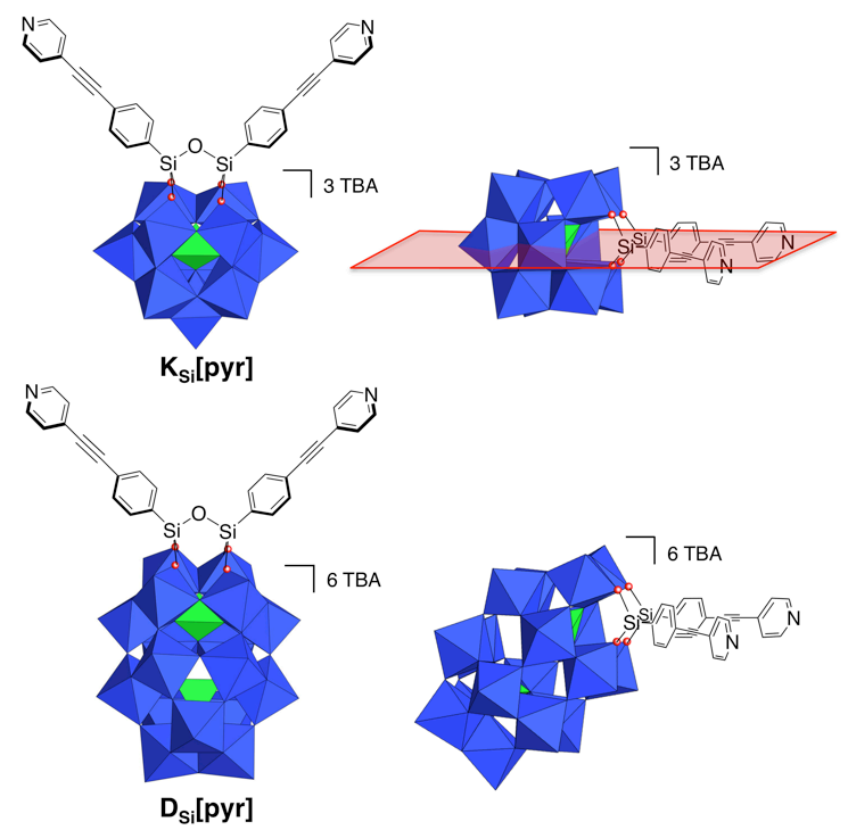

Figure 1. Schematic molecular representations of the hybrids $\mathbf{K}_{\mathrm{si}}[\mathbf{p y r}]$ and $\mathbf{D}_{\mathrm{si}}[\mathbf{p y r}]$ (adapted from X-Ray structures of related compounds) $)^{21-24}$ according to different views. The red plane

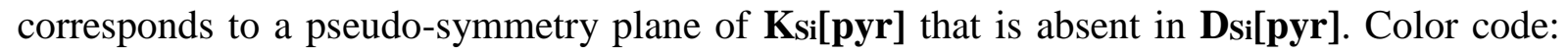
$\mathrm{WO}_{6}$ octahedra, blue; $\mathrm{PO}_{4}$ tetrahedra, green.

The incremental addition of trans-[PdCl$\left(\mathrm{PdeCN}_{2}\right]$ to a solution of $\mathbf{K s i}$ [pyr] (2 $\mathrm{mM}$ in $\mathrm{CD}_{3} \mathrm{CN}$ ) up to $\mathrm{ca}$. 0.5 equiv. mostly leads to the appearance of a single set of signals attributed to coordinated pyridyl units (Figure 2). Between 0.5 and 1.0 equiv. of trans$\left[\mathrm{PdCl}_{2}(\mathrm{MeCN})_{2}\right]$ this set of signals splits into two sets with very close chemical shifts. After the addition of $c a .1$ equiv., the signals of the starting parent hybrid have almost disappeared suggesting that the formed species display a 1:1 stoichiometry between the POM and the Pd unit. At first sight, this behaviour is quite close to the one observed in the Dawson-analogue system, denoted as Dsi[pyr] (Figure 1). ${ }^{20}$ In the previously reported study, two sets of ${ }^{1} \mathrm{H}$ NMR signals were also observed after the addition of 1.0 equivalents of trans[PdCl $2\left(\mathrm{MeCN}_{2}\right]$ to a solution of $\mathbf{D}$ si[pyr]. Diffusion-ordered NMR spectroscopy (DOSY) revealed that both sets of signals decayed similarly thus indicating that they correspond to species of similar shape and size. Furthermore in this previous study, high-resolution ESI-MS only showed peaks corresponding to the molecular triangle $\left.\left[\left(\mathbf{D}_{\mathrm{Si}}[\mathbf{p y r}]\right)_{3} \cdot \mathbf{(} \mathbf{P d C l}_{2}\right)_{3}\right]$ with 
various charge states depending on the number of TBA counter-ions, whereas peaks corresponding to any other bigger oligomer, such as a tetramer, were not observed. The presence of the two sets of signals was attributed to the fact that in the molecular triangle [( $\left.\left.\mathbf{D}_{\text {si }}[\mathbf{p y r}]_{3}\right)_{3}\left(\mathbf{P d C l}_{2}\right)_{3}\right]$, the Dawson unit can present two different orientations with respect to the plane defined by the Pd units. Hence in the molecular triangle displaying a pseudo $\mathrm{C}_{\mathrm{s}}$ symmetry species, the aromatic rings of the organic linker are not chemically equivalent. In the present case, the hybrid Ksi[pyr] display an additional pseudo-symmetry plane, neglecting the inner phosphate, compared to $\mathbf{D}$ si[pyr] (Figure 1). It is thus very unlikely that the presence of the two sets of ${ }^{1} \mathrm{H}$ NMR signals would arise from the different orientations of the POM units with respect to the plane defined by the Pd units.

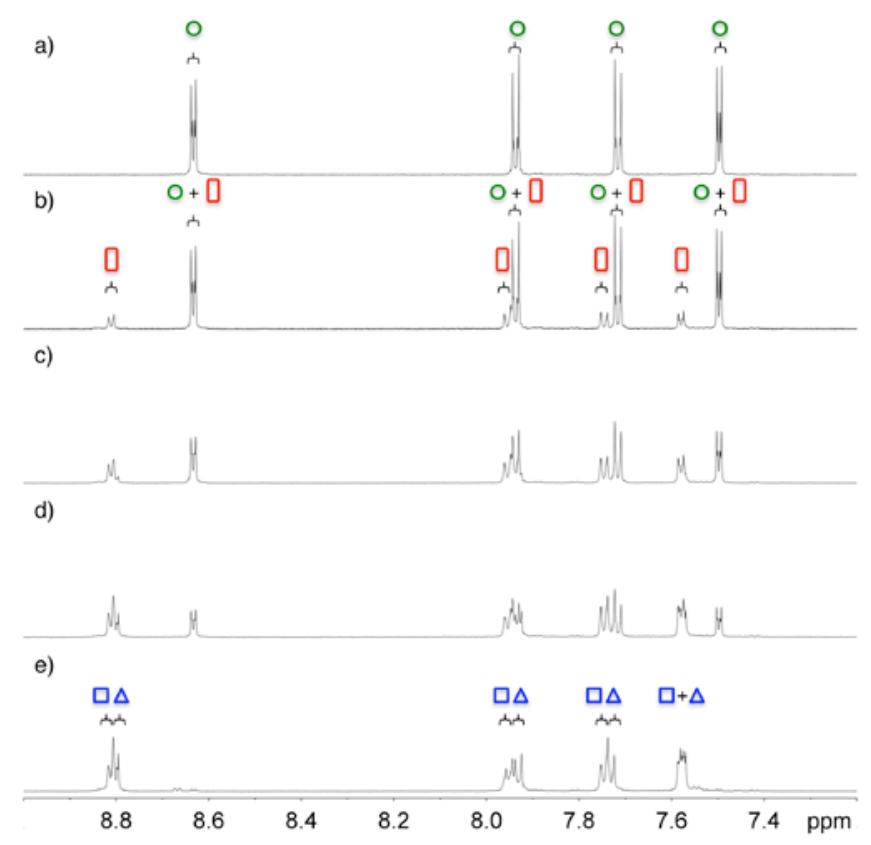

Figure 2. Evolution of the aromatic region of the ${ }^{1} \mathrm{H}$ NMR $(600 \mathrm{MHz})$ spectra of a solution of Ksi[pyr] (2 mM) in $\mathrm{CD}_{3} \mathrm{CN}$ upon titration with trans-[PdCl $2\left(\mathrm{MeCN}_{2}\right]$ : a) 0 equiv.; b) 0.25 equiv.; c) 0.5 equiv., d) 0.75 equiv., e) 1.05 equiv. The circles, rectangles, triangles and

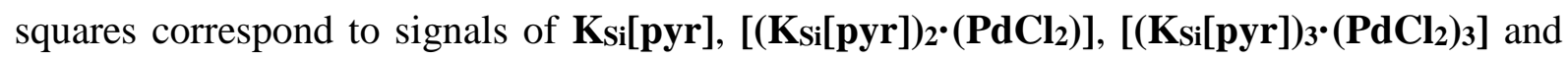

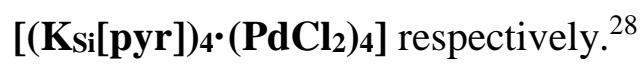

DOSY ${ }^{1} \mathrm{H}$ NMR was performed at different steps during the addition of trans[PdCl $2\left(\mathrm{MeCN}_{2}\right]$ to a solution of $\mathbf{K s i}[\mathbf{p y r}]$ in order to characterize the different species formed upon metal coordination (Table 1). All sets of aromatic signals of $\mathbf{K}_{\text {si }}[\mathbf{p y r}]$ decay similarly according to the pulsed-field gradient strengths with a unique diffusion coefficient $\mathrm{D}_{1}=$ $8.6 \times 10^{-10} \mathrm{~m}^{2} . \mathrm{s}^{-1}$ (Figure S2). Interestingly, the diffusion coefficient of the TBA counter-ions $\left(D_{\text {TBA }}=1.50 \times 10^{-9} \mathrm{~m}^{2} \cdot \mathrm{s}^{-1}\right.$, Figure S2) is higher than that of the POM-based hybrid, suggesting 
that in acetonitrile, the TBA are not tightly associated to the POM. Upon the addition of 0.25 equiv. of trans-[ $\left.\mathrm{PdCl}_{2}(\mathrm{MeCN})_{2}\right]$, the new doublets at 7.57, 7.75 and $8.80 \mathrm{ppm}$ display a unique diffusion coefficient $\mathrm{D}_{2}=5.0 \times 10^{-10} \mathrm{~m}^{2} \cdot \mathrm{s}^{-1}$ (Table 1, Figure S4), a value that is slightly smaller than the diffusion coefficient of the starting building block. Furthermore the diffusion coefficient of the signals corresponding to the uncoordinated arms show an apparent weak decrease compared to $\mathbf{K}_{\text {si }}[\mathbf{p y r}]$ (Figure S5), while their decay vs the pulsed-field gradient strength cannot be satisfactorily modelled by using a single diffusion coefficient but by a twocomponent with $\mathrm{D}_{1}$ and $\mathrm{D}_{2}$ (Figures $\mathrm{S} 5$ \& S6). In the previous study, the ratio of the diffusion coefficient of the free molecular building block to that of the molecular triangle [( $\left.\mathbf{D}_{\text {si }}[\mathbf{p y r}]_{)_{3}} \cdot\left(\mathbf{P d C l}_{2}\right)_{3}\right]$ was 2.3. The modest difference between $\mathrm{D}_{1}$ and $\mathrm{D}_{2}$ indicates that the first species formed at low concentration of trans-[ $\left.\mathrm{PdCl}_{2}(\mathrm{MeCN})_{2}\right]$ is smaller than a trimer and more probably corresponds to the dimer [(Ksi[pyr])2・(PdCl 2$)]$ (Figure 3). This species contains uncoordinated ligands, which display ${ }^{1} \mathrm{H}$ NMR signals similar to those of $\mathbf{K s i}[\mathbf{p y r}]$. This explains the apparent decrease of the diffusion coefficient of the signals at 7.50, 7.72 and $8.63 \mathrm{ppm}$ in the presence of 0.25 equiv. of trans-[ $\left.\mathrm{PdCl}_{2}(\mathrm{MeCN})_{2}\right]$. The fact that the dimer [(KSi[pyr] $\left.)_{2} \cdot\left(\mathbf{P d C l}_{2}\right)\right]$ is the dominant species at intermediate concentration of trans$\left[\mathrm{PdCl}_{2}(\mathrm{MeCN})_{2}\right]$ suggests that the formation of the cyclic assembly is a non-cooperative process, ${ }^{29}$ probably owing to a high entropic term that is not compensated by the chelate cooperativity.

Table 1. Diffusion constant of selected peaks during the addition of trans-[ $\mathrm{PdCl}_{2}\left(\mathrm{MeCN}_{2}\right]$ to a solution of $\mathbf{K s i}_{\mathrm{si}}[\mathbf{p y r}]$.

$\left[\mathrm{PdCl}_{2}\left(\mathrm{MeCN}_{2}\right]\right.$

$\delta / \mathrm{ppm}\left(\mathrm{D} \times 10^{-10} / \mathrm{m}^{2} \cdot \mathrm{s}^{-1}\right)$ assignment

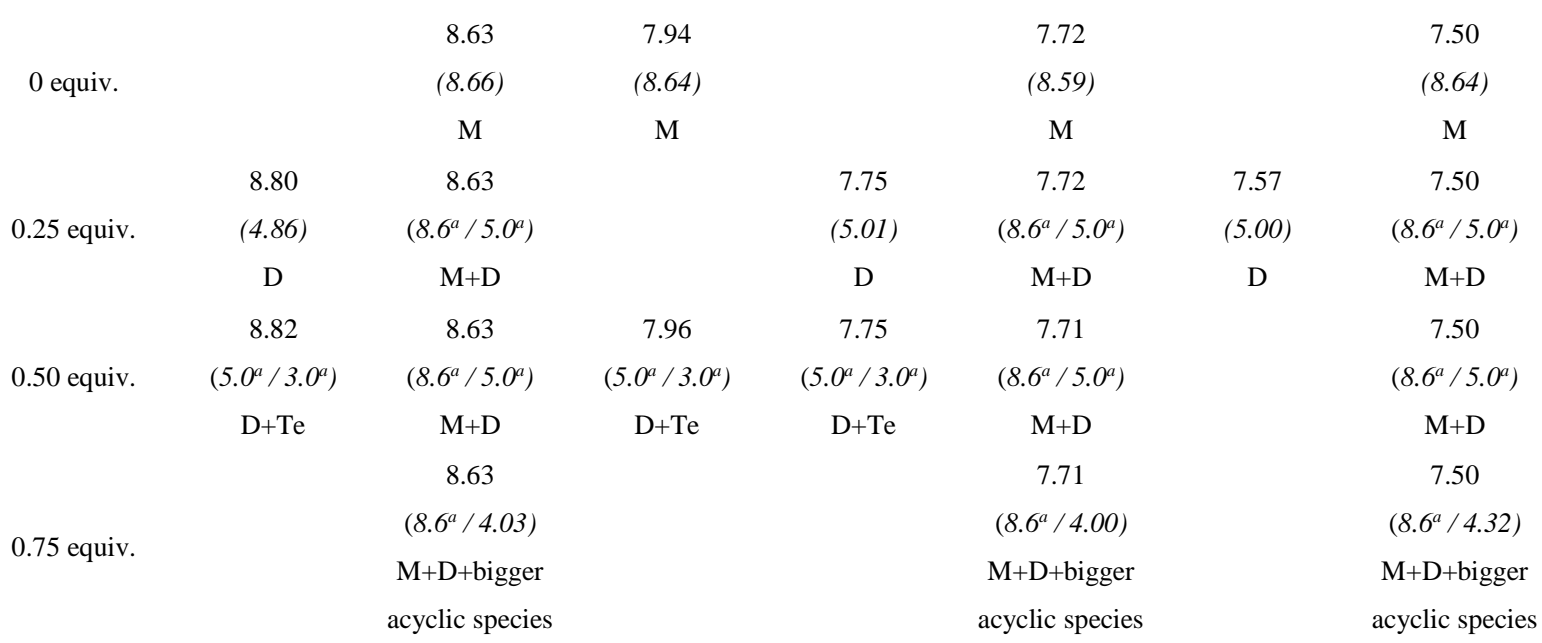




\begin{tabular}{|c|c|c|c|c|c|c|}
\hline \multirow{3}{*}{1.05 equiv. } & 8.82 & 8.80 & 7.96 & 7.93 & 7.75 & 7.72 \\
\hline & (2.93) & (3.58) & (3.01) & (3.74) & (3.08) & (3.64) \\
\hline & $\mathrm{Te}$ & $\operatorname{Tr}$ & $\mathrm{Te}$ & $\operatorname{Tr}$ & $\mathrm{Te}$ & $\operatorname{Tr}$ \\
\hline
\end{tabular}

Upon the addition of 0.5 equivalent of trans-[$\left[\mathrm{PdCl}_{2}(\mathrm{MeCN})_{2}\right]$, the decay of the signals at 7.50, 7.71 and $8.63 \mathrm{ppm}$ (corresponding to non-coordinated organic linkers) can still be fitted by a double component with $\mathrm{D}_{1}=8.6 \times 10^{-10} \mathrm{~m}^{2} \cdot \mathrm{s}^{-1}$ and $\mathrm{D}_{2}=5.0 \times 10^{-10} \mathrm{~m}^{2} \cdot \mathrm{s}^{-1}$ (Figure S8). $\mathrm{K}_{\text {si }}[\mathbf{p y r}$ ]

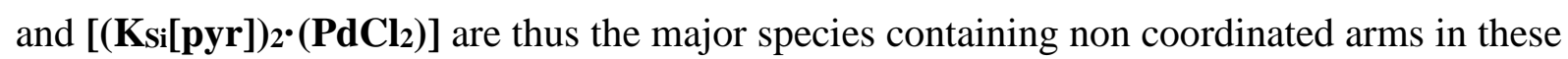
conditions. When 0.75 equivalent of trans-[ $\mathrm{PdCl}_{2}\left(\mathrm{MeCN}_{2}\right]$ are added to $\mathbf{K s i}$ [pyr], the decay of these signals at 7.50, 7.71 and $8.63 \mathrm{ppm}$ cannot be satisfactorily fitted with $\mathrm{D}_{1}=8.6 \times 10^{-10}$ $\mathrm{m}^{2} \cdot \mathrm{s}^{-1}$ and $\mathrm{D}_{2}=5.0 \times 10^{-10} \mathrm{~m}^{2} \cdot \mathrm{s}^{-1}$, but with values of $8.6 \times 10^{-10} \mathrm{~m}^{2} \cdot \mathrm{s}^{-1}$ and $4.1 \times 10^{-10} \mathrm{~m}^{2} \cdot \mathrm{s}^{-1}$ (Figure S11). This suggests that bigger acyclic oligomers can be present at this stage of the titration. Finally, upon the addition of a very slight excess of trans-[ $\mathrm{PdCl}_{2}\left(\mathrm{MeCN}_{2}\right](1.05$ equiv.) the two sets of signals corresponding to species with a 1:1 stoichiometry do not decay similarly indicating thus that they correspond to species of different sizes and compositions. The peaks at 7.72, 7.93 and $8.80 \mathrm{ppm}$ can be nicely fitted with a single component $\mathrm{D}_{3}=$ $3.7 \times 10^{-10} \mathrm{~m}^{2} . \mathrm{s}^{-1}$ (Figure S13) while those at $7.75,7.96$ and $8.82 \mathrm{ppm}$ also give a unique diffusion coefficient $\mathrm{D}_{4}=3.0 \times 10^{-10} \mathrm{~m}^{2} \cdot \mathrm{s}^{-1}$ (Figure S14). Interestingly the $\mathrm{D}_{1} / \mathrm{D}_{3}$ ratio is 2.3 , i.e. the value found for the molecular triangle formed from $\mathbf{D}_{\text {si }}[\mathbf{p y r}]{ }^{20}$ The $\mathrm{D}_{4}$ value, significantly smaller than $\mathrm{D}_{3}$, is thus attributed to the presence of a bigger species, most probably a molecular square. Note that the decay of the signals of the coordinated arms at 7.75, 7.96 and $8.82 \mathrm{ppm}$ in the presence of 0.5 equiv. of trans-[ $\left.\mathrm{PdCl}_{2}(\mathrm{MeCN})_{2}\right]$ can nicely be fitted by a double component with $\mathrm{D}_{2}$ and $\mathrm{D}_{4}$, attesting the presence of the tetramer at this stage of the titration (Figure S9). NMR integration of the aromatic signals allows estimating the species distribution during the addition of trans- $\left[\mathrm{PdCl}_{2}\left(\mathrm{MeCN}_{2}\right)_{2}\right.$ to $\mathbf{K s i}$ [pyr] (Figure 3, Table S1). ${ }^{30}$ In practice, the ratio between the integration of the signals at $7.57 \mathrm{ppm}$ and 8.80 $8.82 \mathrm{ppm}$ versus those at $7.50 \mathrm{ppm}$ and $8.63 \mathrm{ppm}$ give the proportion of coordinated pyridine versus uncoordinated pyridine, while the proportion of the peak at $8.80 \mathrm{ppm}$ within the overall signal at 8.80-8.82 ppm allows estimating the ratio between the different coordination oligomers. The comparison of the integration of all aromatics signals versus those of the TBA cations shows a slight decrease of $c a .10 \%$ after the addition of 1.05 equiv. of trans$\left[\mathrm{PdCl}_{2}(\mathrm{MeCN})_{2}\right]$. This loss in the NMR signals is attributed to the minor formation of oligomeric species displaying Pd / POM ratio higher than 1. Finally the two sets of signals at $7.93 \mathrm{ppm}$ and $7.96 \mathrm{ppm}$ (corresponding to the triangle and the square respectively) after the 
addition of 1.05 equiv. of trans-[ $\left.\mathrm{PdCl}_{2}(\mathrm{MeCN})_{2}\right]$ have similar integration indicating an identical distribution of the hybrid within its triangle and square forms.

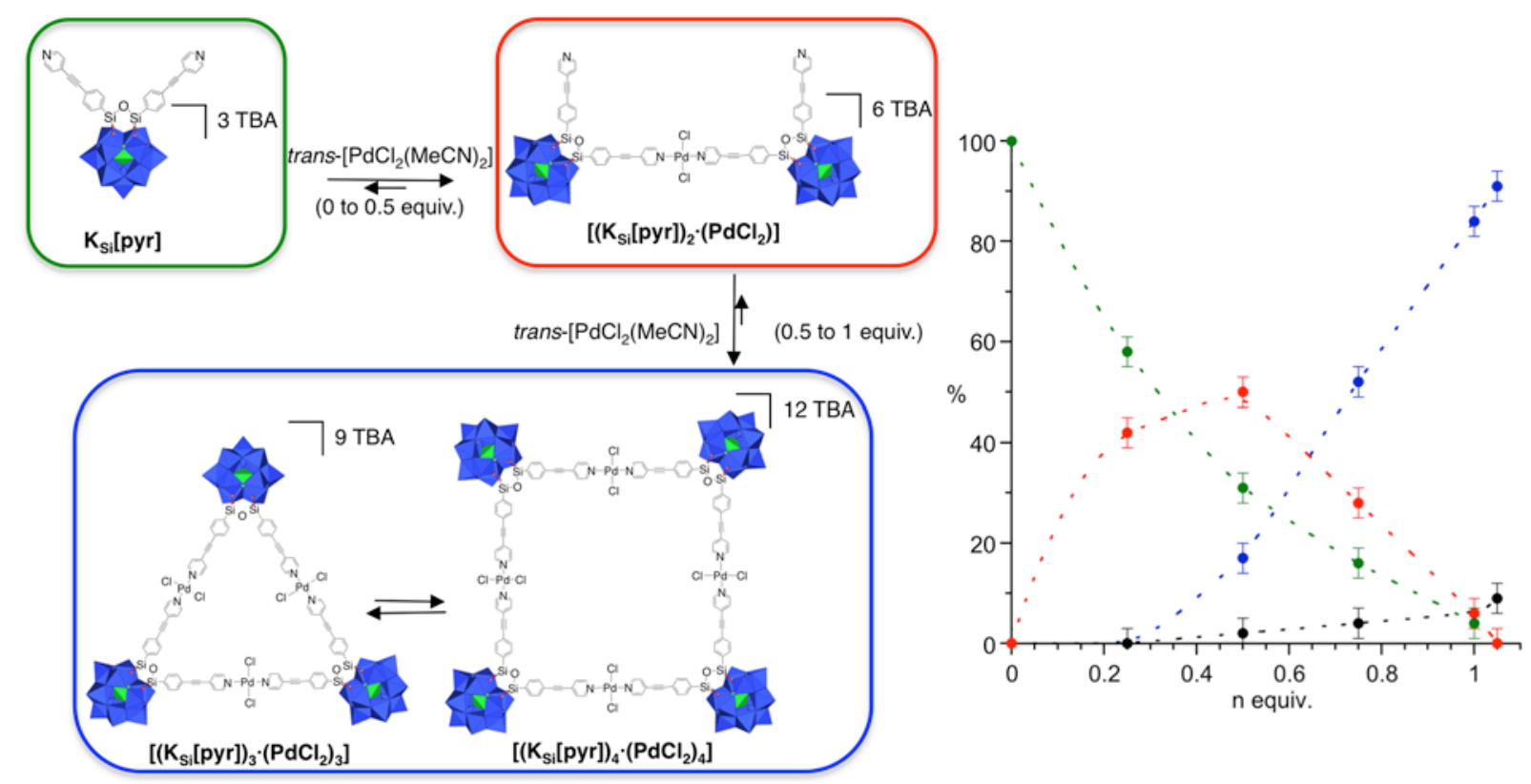

Figure 3. Left) Metal driven formation of the molecular triangle and square from the POM hybrid $\mathbf{K s i}_{\mathrm{si}}\left[\mathrm{pyr}\right.$. Right) Species distribution during the addition of trans-[ $\mathrm{PdCl}_{2}\left(\mathrm{MeCN}_{2}\right]$ on a solution of $\mathbf{K s i}[\mathbf{p y r}]$ in $\mathrm{CD}_{3} \mathrm{CN}$; green: $\mathbf{K s i}[\mathbf{p y r}]$, red: $\left[\left(\mathrm{Ksi}_{\mathbf{i}}[\mathbf{p y r}]\right) \mathbf{2}^{\cdot}\left(\mathbf{P d C l}_{2}\right)\right]$, blue:

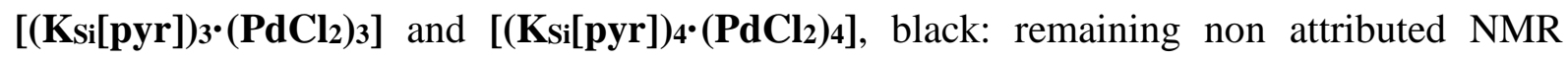
signals. ${ }^{19}$

High-resolution ESI-MS was performed on a $10 \mu \mathrm{M}$ solution of $\mathbf{K s i}$ [pyr] in the presence of 1.0 equivalent of trans-[ $\mathrm{PdCl}_{2}\left(\mathrm{MeCN}_{2}\right]$ in $\mathrm{MeCN}$. This $10 \mu \mathrm{M}$ solution was obtained from a $2 \mathrm{mM}$ solution similar to that analysed by NMR which was diluted a few minutes prior to the analysis. The resulting mass spectrum confirmed the stoichiometry of the species formed upon metal coordination. The mass spectrum mostly shows peaks that correspond to the trimer [(Ksi[pyr])3 $\left.\cdot\left(\mathbf{P d C l}_{2}\right)_{3}\right](\mathrm{Tr})$ with charge states 5- to 10-, depending on the number of TBA counterions attached ((Figure 4 and Figure S15). The other major peaks observed correspond to the tetramer $\left[\left(\mathrm{Ksi}_{\mathbf{S}}[\mathbf{p y r}]\right)_{4} \cdot \mathbf{(}\left(\mathbf{P d C l}_{2}\right)_{4}\right]$ (Te, Figure S16), the dimer [(Ksi[pyr])2・(PdCl2)] (D, Figure S17), the monomer Ksi[pyr] (M, Figure S18). Additional minor signals corresponding to the dimer with an additional $\mathrm{PdCl}_{2}\left[\left(\mathbf{K s i}_{\mathrm{Si}}[\mathbf{p y r}]\right)_{2} \cdot\left(\mathbf{P d C l}_{2}\right)\right]\left(\mathrm{D}^{*}\right)$ and the monomer with $\mathrm{PdCl}_{2}$ [(KSi[pyr])・(PdCl$\left.)\right]\left(\mathbf{M}^{*}\right)$ were also observed. Relative quantification of the species present in the solution from this mass spectrum is delicate because each oligomer appears with several charge states that all have different response factors so that the relative intensities cannot be considered directly proportional to their 
relative quantities in solution. In addition, some oligomers ( $\operatorname{Tr}$ and $\mathrm{M}^{*}$ or Te and $\mathrm{D}^{*}$ ) appear at identical $\mathrm{m} / \mathrm{z}$ values (Figures S15a, S15b, S16a). The last minute dilution and the instrumental parameters (electrospray ionization and ion transmission), although chosen to minimize any dissociation may also be responsible for the minor formation of the additional oligomer $\mathrm{M}^{*}$ and $\mathrm{D}^{*}$ that were not considered with NMR. Nevertheless, this study confirmed the concomittant formation of molecular triangles and squares in the presence of 1 equiv. of trans-[ $\left.\mathrm{PdCl}_{2}(\mathrm{MeCN})_{2}\right]$.

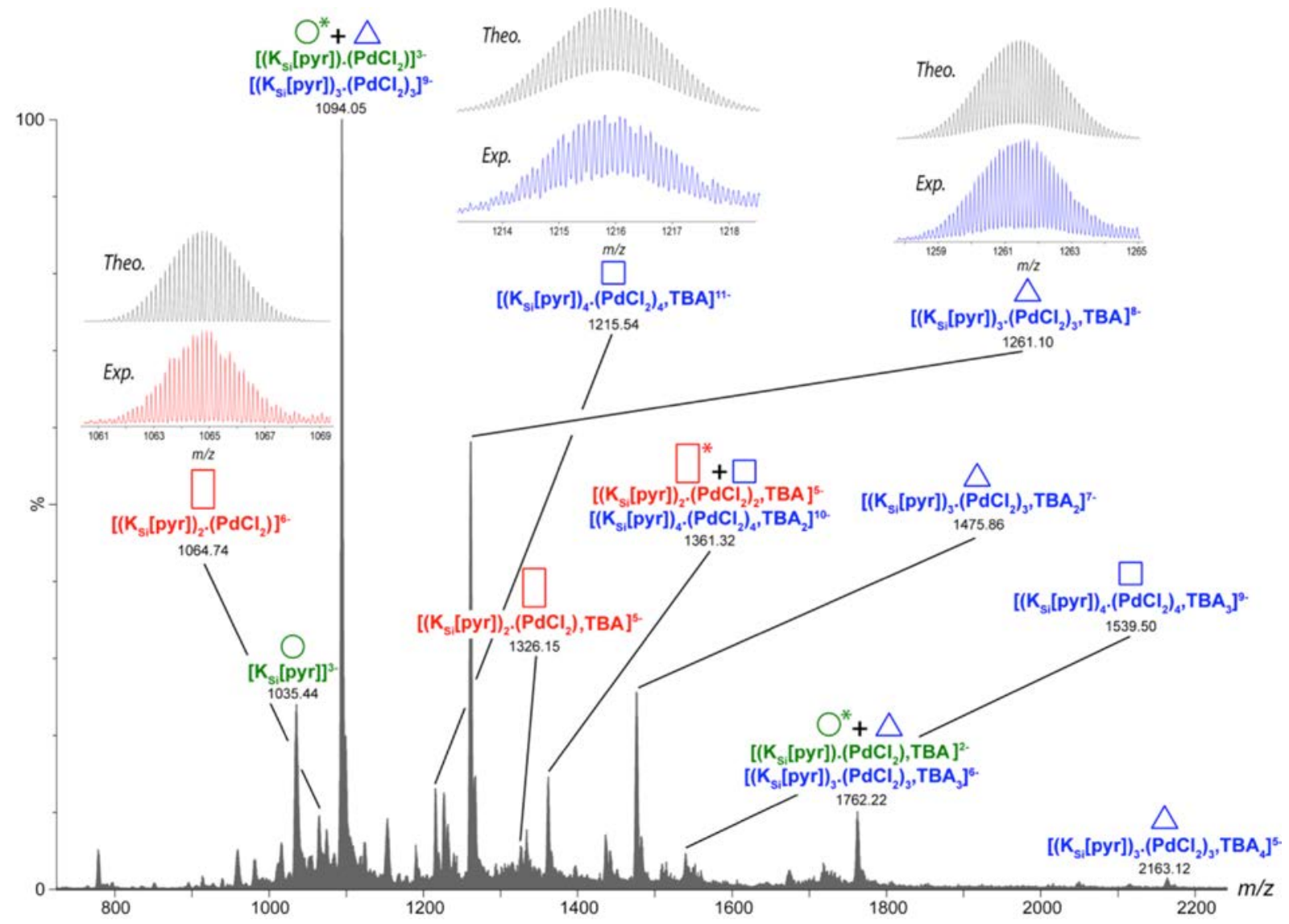

Figure 4. ESI mass spectrum of a solution of $\mathbf{K}_{\mathrm{si}}[\mathrm{pyr}](10 \mu \mathrm{M})$ and trans-[PdCl $2\left(\mathrm{MeCN}_{2}\right](1$ equiv.) in MeCN. The main ion distribution corresponds to the molecular triangles and squares with a varying number of TBA counterions. Inset: Comparison of experimental (lower trace) and calculated (upper trace) isotopic distributions for m/z 1065, 1216 and 1261.

High-resolution ESI-MS was also performed on a $10 \mu \mathrm{M}$ solution of $\mathbf{K s i}[\mathbf{p y r}$ ], in the presence of 0.5 equivalent of trans-[ $\mathrm{PdCl}_{2}\left(\mathrm{MeCN}_{2}\right]$ in $\mathrm{MeCN}$ (Figure S19). Similarly, this $10 \mu \mathrm{M}$ solution was obtained from a $2 \mathrm{mM}$ solution and was diluted a few minutes prior to the analysis. Besides the major peaks of the starting monomer $\mathbf{K s i}[\mathbf{p y r}]$, the mass spectrum mostly shows peaks corresponding to the dimer [(Ksi[pyr]) $\left.\mathbf{2}^{\cdot}\left(\mathbf{P d C l}_{2}\right)\right]$ (D) with charge states 
4- to 6- and the monomer with an additional $\mathrm{PdCl}_{2}\left[\left(\mathbf{K s i}_{\mathrm{si}}[\mathbf{p y r}]\right) \cdot\left(\mathbf{P d C l}_{2}\right)\right]\left(\mathbf{M}^{*}\right)$. Only traces of the trimer $\left[\left(\mathbf{K}_{\text {si }}[\mathbf{p y r}]_{3}\right)_{3}\left(\mathbf{P d C l}_{2}\right)_{3}\right](\mathrm{Tr})$ were detected (Figure S20). This further evidenced that the metallomacrocycle species are hardly present at this intermediate ratio of trans$\left[\mathrm{PdCl}_{2}(\mathrm{MeCN})_{2}\right]$.

\section{Correlation between diffusion coefficient and molecular weight}

A power law between the diffusion coefficient $D$ and the molecular mass $M$ for a series of similar molecules has often been observed. ${ }^{31}$

$D \propto \mathrm{M}^{-1 / d_{\mathrm{F}}}$

with $d_{\mathrm{F}}$ being the fractal dimension of the molecular object. This correlation allows to predict the molecular mass from the diffusion coefficient without using complex optimized structures that are computationally challenging when dealing with large POM assemblies. ${ }^{19}$ The fractal dimension can be seen as an indicator of the way an object fills up in the 3D space. This value ranges from 1 to 3 for purely one-dimensional objects and solid spheres respectively. This relation was applied to a wide range of cyclic POMs. ${ }^{32}$ In this case a fractal dimension of 2.96 was observed, very close to the theoretical $d_{\mathrm{F}}=3$ value expected for perfect spheres. In the present case, owing to the high anisotropy of the POM-based building block Ksi[pyr], the fractal dimension is expected to be considerably lower. Furthermore, Ksi[pyr] and its coordination oligomers have different shapes, [(Ksi[pyr])2・(PdCl $\mathbf{2})]$ mostly featuring a linear shape, while the molecular triangle and square are cyclic assemblies, suggesting that the simple correlation of equation (1) may not be valid for this series of compounds. However, as shown in Figure 5, the relation of $\log D v s \log M$ is linear with a slope of -0.735 , giving a fractal dimension $d_{\mathrm{F}}=1.36$. The fact that the power law between the diffusion coefficient $D$ and the molecular mass $M$ is applicable to this series of compounds, indicates that the shape of the molecular assembly has little effect on the diffusion coefficient and that the diffusion coefficient is probably mainly determined by the volume occupied by the compound. In other words for these discrete molecular assemblies, there is no need for complex models which would take into account the shape of the molecule. A similar observation has been previously done when comparing the diffusion coefficient of acyclic and macrocyclic drug-like molecules. $^{33}$ 


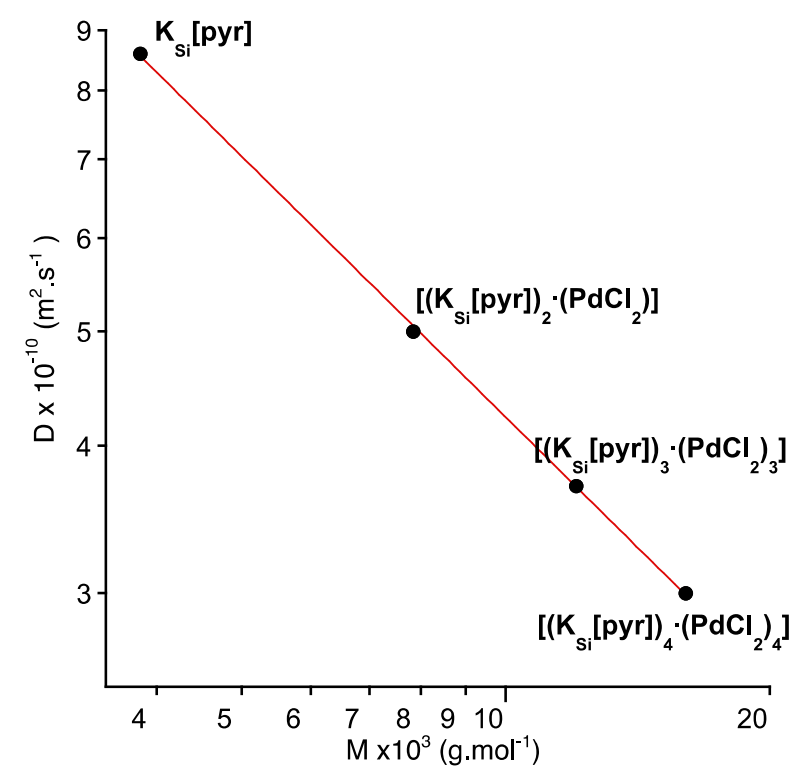

Figure 5. Relationship between diffusion coefficient and mass for $\mathbf{K}_{\text {si }}[\mathbf{p y r}]$ and its coordination oligomers.

\section{Comparison of complexation energy between Keggin type and Dawson type POM-based}

\section{hybrids}

In order to probe the thermodynamics of the formation of these complexes, an isothermal titration calorimetry (ITC) experiment was performed: ${ }^{34}$ trans-[ $\left.\mathrm{PdCl}_{2}(\mathrm{MeCN})_{2}\right]$ was incrementally injected into a $1 \mathrm{mM}$ solution of $\mathbf{K s i}$ [pyr] (or $\mathbf{D}_{\text {si }}[\mathbf{p y r}$ ], respectively) in MeCN. The resulting exothermal heat effects are displayed on Figure 5 and qualitatively show an inflection point at a molar ratio of 1 , which implies that (for both systems) the stoichiometry of the assembly is $1: 1$. Moreover, the steeper slope in the case of $\mathbf{K} \mathbf{s i}[\mathbf{p y r}]$ indicates a stronger association for the Keggin-based system. Quantitative analysis of the data is tricky because (i) both sites on the Pd atom are probably dependent ${ }^{35}$ and (ii) our NMR and ESI results unambiguously show that the self-assembly process involves several intermediates and products. Nevertheless, we tested whether the simplest association model considering a single set of identical binding sites could quantitatively describe the experiments. In other words, we analyse the data at the level of the elementary binding sites, without taking into account any possible interference between them:

$\mathrm{L}+\mathrm{n} \mathrm{M} \leftrightarrow \mathrm{M}_{\mathrm{n}} \mathrm{L}$

where L stands for one pyridine function of the ligand ([L] = 2[Ksi[pyr] $]$ ) and $\mathrm{M}$ stands for one binding site of the $\mathrm{Pd}(\mathrm{II})$ metal $\left([\mathrm{M}]=2\left[\right.\right.$ trans- $\left.\left.\left[\mathrm{PdCl}_{2}(\mathrm{MeCN})_{2}\right]\right]\right)$. The results from the fits are displayed on Figure 5 and the values of fitted parameters are summarized in Table 2. The 
agreement between the data and this crude model is not perfect, but the slight discrepancy does not allow the use of a more elaborate model that would necessarily involve additional adjustable parameters. As expected, the stoichiometry of the interaction is 1:1 (i.e. one ditopic ligand to one ditopic metal) and the assembly is enthalpically-driven and entropicallyopposed.

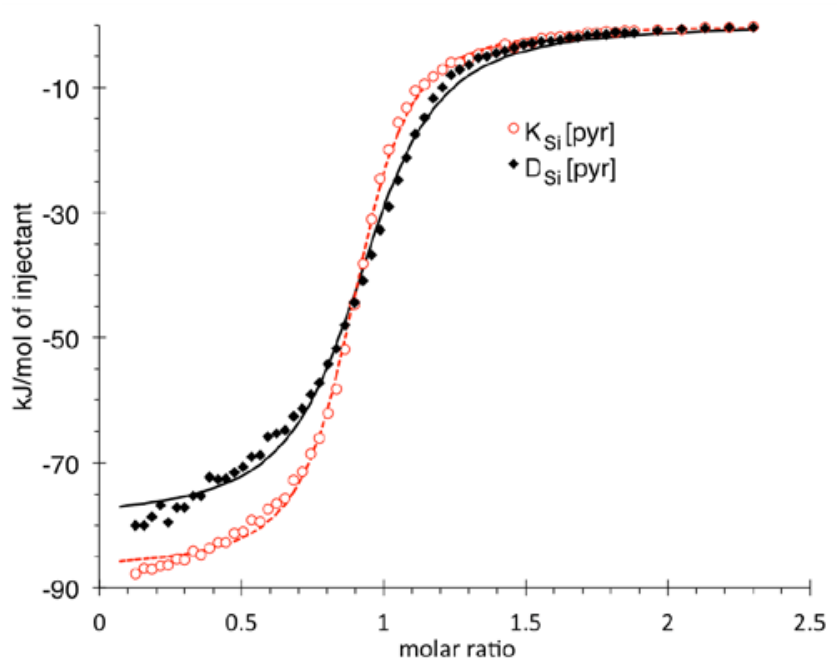

Figure 6. ITC enthalpogram obtained by injecting a trans- $\left[\mathrm{PdCl}_{2}\left(\mathrm{MeCN}_{2}\right]\right.$ solution in $\mathrm{MeCN}$ (10 mM) into a $\mathbf{K s i}_{\mathrm{si}}[\mathbf{p y r}]$ (or $\mathbf{D}_{\mathrm{si}}[\mathrm{pyr}]$ ) solution in $\mathrm{MeCN}(1 \mathrm{mM})$ at $25^{\circ} \mathrm{C}$. The lines correspond to fits according to a model considering a single set of identical sites.

The fit indicates a stronger binding in the case of the Keggin oxo-cluster that it is assigned to a more enthalpically favourable interaction. In Ksi[pyr] an identical distribution of the hybrid within its triangle and square forms are observed while only molecular triangles were detected with Dsi[pyr]. Consequently we assign the difference in binding enthalpy between $\mathbf{K s i}$ [pyr] and $\mathbf{D}_{\text {si }}[\mathbf{p y r}]$ to reduced constrains in the molecular square that is only present with $\mathbf{K}$ si[pyr]. Weaker electrostatic repulsions between the POM building blocks forming the cyclic oligomers may also account for the stronger binding in the case of the Keggin oxo-cluster. The entropy formation in the self assembly of $\mathbf{K s i}[\mathbf{p y r}]$ and $\mathbf{D s i}[\mathbf{p y r}]$ is close while the formation of the tetramer vs trimer may have a significant difference of entropy. ${ }^{36}$ The lower charge of Ksi[pyr] compared to $\mathbf{D s i}[\mathbf{p y r}]$ probably counter-balances the gain associated with the formation of the tetramer. Further studies on simpler systems (e.g. complexation of monotopic hybrids with a single metal ion) will be further investigated to evaluate more precisely the effect of the charge of the POM on the entropy reaction. 
Table 2. Thermodynamic parameters for the binding of POM ligands to trans$\left[\mathrm{PdCl}_{2}(\mathrm{MeCN})_{2}\right]$, deduced from Figure 5.

$\begin{array}{llllll}\text { Ligand } & \mathrm{N} & \mathrm{K} / \mathrm{M}^{-1} & \Delta \mathrm{H} / \mathrm{kJ} / \mathrm{mol}^{-1} & \Delta \mathrm{G} / \mathrm{kJ}^{-\mathrm{mol}^{-1}} & \mathrm{~T} \Delta \mathrm{S} / \mathrm{kJ}^{\mathrm{mol}}{ }^{-1} \\ \mathbf{K}_{\mathrm{si}}[\mathrm{pyr}] & 0.90 & 4.6210^{4} & -43.5 & -26.5 & -16.9 \\ \mathbf{D}_{\mathrm{Si}}[\mathbf{p y r}] & 0.93 & 2.4610^{4} & -39.5 & -25.0 & -14.4\end{array}$

\section{Conclusions}

We have synthesized new supramolecular polygons from a Keggin-based molecular building block through metal-directed self-assembly. These species consist of a mixture of molecular triangles and squares while in a previous study using a higher charged building block, only molecular triangles were formed. This studies outline the decisive effect of the charge of the POM disfavouring the formation of large assemblies. The formation of highly charged supramolecular species (e.g., a Dawson-based tetramer) is most likely hindered by an important entropic contribution. This finding will help us to develop larger POM-based supramolecular assemblies. While the Keggin-based molecular building block and its coordination oligomers display different shapes a power law between the diffusion coefficient $D$ and the molecular mass $M$ is applicable to this series of hybrids. This indicates that the diffusion coefficient of these compounds is mainly determined by their occupied volume rather than by their shape. This simple model will allow to efficiently estimating the stoichiometry of a POM-based assembly only thanks to its diffusion coefficient.

\section{Experimental Section}

Trans-[PdCl $2\left(\mathrm{MeCN}_{2}\right], \mathbf{K}_{\text {si }}[\mathbf{p y r}]$ and $\mathbf{D}$ si[pyr] were prepared according to published procedures. $^{20,27,37}$ All other reagents were used as supplied.

NMR spectra were recorded either on a Bruker Avance III 600 spectrometer equipped with a BBFO probe head. The $1 \mathrm{H}$ DOSY spectra were acquired by using the pulse sequence ledbpgp2s. The gradient strength $G$ was varied in 16 linear steps from 2.49 to $47.3 \mathrm{G} \mathrm{cm}^{-1}$ to ensure at least $90 \%$ signal attenuation. The spectra were processed by using the fitting routine integrated in the TopSpin3.5 package.

Mass spectrometry experiments were carried out by using a Synapt G2 HDMS (Waters, Manchester, UK) instrument equipped with an electrospray ionization source, which was operated in the negative ion mode. All desolvation, transmission parameters were tuned to 
limit gas-phase ion fragmentation. Mass spectra were processed with MassLynx 4.1 and the theoretical isotopic patterns were predicted using mMass 5.5.0. ${ }^{38}$

ITC data were recorded on a MicroCal VP-ITC apparatus at $25^{\circ} \mathrm{C}$, injecting a $10^{-2} \mathrm{M}$ trans$\left[\mathrm{PdCl}_{2}\left(\mathrm{MeCN}_{2}\right]\right.$ solution in MeCN into a $10^{-3} \mathrm{M} \mathrm{Ksi[pyr]} \mathrm{(or} \mathbf{D}_{\mathrm{si}}[\mathbf{p y r}]$ ) solution in MeCN. Injections of $4 \mu \mathrm{L}$ over 20 seconds were performed every 900 seconds at a stirring rate of 300 rpm. The heat of dilution of trans-[PdCl $\left.2(\mathrm{MeCN})_{2}\right]$ was measured in the same conditions and was confirmed to be negligible. The data were fitted with MicroCal software.

\section{Supporting Information available.}

Fits of the DOSY NMR spectra, comparison of experimental and calculated isotopic distributions of the ESI mass spectrum.

\section{Acknowledgements}

This work was supported by the French National Research agency (EXPAND, ANR-14CE08-0002) and the Labex SynOrg (ANR-11-LABX-0029).

1. Fujita, M.; Tominaga, M.; Hori, A.; Therrien, B. Coordination assemblies from a Pd(II)-cornered square complex. Acc. Chem. Res. 2005, 38, 369-378.

2. Northrop, B. H.; Zheng, Y. R.; Chi, K. W.; Stang, P. J. Self-Organization in Coordination-Driven Self-Assembly. Acc. Chem. Res. 2009, 42, 1554-1563.

3. Smulders, M. M. J.; Riddell, I. A.; Browne, C.; Nitschke, J. R. Building on architectural principles for three-dimensional metallosupramolecular construction. Chem. Soc. Rev. 2013, 42, 1728-1754.

4. Chen, L.; Chen, Q. H.; Wu, M. Y.; Jiang, F. L.; Hong, M. C. Controllable Coordination-Driven Self-Assembly: From Discrete Metallocages to Infinite Cage-Based Frameworks. Acc. Chem. Res. 2015, 48, 201-210.

5. Wang, W.; Wang, Y. X.; Yang, H. B. Supramolecular transformations within discrete coordination-driven supramolecular architectures. Chem. Soc. Rev. 2016, 45, 2656-2693.

6. Lescop, C. Coordination-Driven Syntheses of Compact Supramolecular Metallacycles toward Extended Metallo-organic Stacked Supramolecular Assemblies. Acc. Chem. Res. 2017, 50, 885-894.

7. Busche, C.; Vila-Nadal, L.; Yan, J.; Miras, H. N.; Long, D. L.; Georgiev, V. P.; Asenov, A.; Pedersen, R. H.; Gadegaard, N.; Mirza, M. M.; Paul, D. J.; Poblet, J. M.; Cronin, L. Design and fabrication of memory devices based on nanoscale polyoxometalate clusters. Nature 2014, 515, 545-549.

8. $\quad$ Ji, Y. C.; Huang, L. J.; Hu, J.; Streb, C.; Song, Y. F. Polyoxometalate-functionalized nanocarbon materials for energy conversion, energy storage and sensor systems. Energy Environ. Sci. 2015, 8, 776-789.

9. Song, Y. F.; Tsunashima, R. Recent advances on polyoxometalate-based molecular and composite materials. Chem. Soc. Rev. 2012, 41, 7384-402. 
10. Miras, H. N.; Yan, J.; Long, D. L.; Cronin, L. Engineering polyoxometalates with emergent properties. Chem. Soc. Rev. 2012, 41, 7403-30.

11. Izzet, G.; Volatron, F.; Proust, A. Tailor-made Covalent Organic-Inorganic Polyoxometalate Hybrids: Versatile Platforms for the Elaboration of Functional Molecular Architectures. Chem. Rec. 2017, 250-266.

12. Luisi, P. Emergence in Chemistry: Chemistry as the Embodiment of Emergence. Foundations of Chemistry 2002, 4, 183-200.

13. Mainzer, K.; Müller, A.; Saltzer, W. G. From Simplicity to Complexity Part II Information - Interaction - Emergence. Vieweg Publishing: Wiesbaden, 1996.

14. Yue, L.; Wang, S.; Zhou, D.; Zhang, H.; Li, B.; Wu, L. X. Flexible single-layer ionic organic-inorganic frameworks towards precise nano-size separation. Nat Commun 2016, 7,

15. Izzet, G.; Menand, M.; Matt, B.; Renaudineau, S.; Chamoreau, L. M.; Sollogoub, M.; Proust, A. Cyclodextrin-Induced Auto-Healing of Hybrid Polyoxometalates. Angew. Chem., Int. Ed. 2012, 51, 487-490.

16. Parrot, A.; Bernard, A.; Jacquart, A.; Serapian, S. A.; Bo, C.; Derat, E.; Oms, O.; Dolbecq, A.; Proust, A.; Metivier, R.; Mialane, P.; Izzet, G. Photochromism and Dual-Color Fluorescence in a Polyoxometalate-Benzospiropyran Molecular Switch. Angew. Chem., Int. Ed. 2017, 56, 4872-4876.

17. Yin, P. C.; Wu, P. F.; Xiao, Z. C.; Li, D.; Bitterlich, E.; Zhang, J.; Cheng, P.; Vezenov, D. V.; Liu, T. B.; Wei, Y. G. A Double-Tailed Fluorescent Surfactant with a Hexavanadate Cluster as the Head Group. Angew. Chem., Int. Ed. 2011, 50, 2521-2525.

18. Cooper, G. J. T.; Boulay, A. G.; Kitson, P. J.; Ritchie, C.; Richmond, C. J.; Thiel, J.; Gabb, D.; Eadie, R.; Long, D. L.; Cronin, L. Osmotically Driven Crystal Morphogenesis: A General Approach to the Fabrication of Micrometer-Scale Tubular Architectures Based on Polyoxometalates. J. Am. Chem. Soc. 2011, 133, 5947-5954.

19. Izzet, G.; Abécassis, B.; Brouri, D.; Piot, M.; Matt, B.; Serapian, S. A.; Bo, C.; Proust, A. Hierarchical Self-Assembly of Polyoxometalate-Based Hybrids Driven by Metal Coordination and Electrostatic Interactions: From Discrete Supramolecular Species to Dense Monodisperse Nanoparticles. J. Am. Chem. Soc. 2016, 138, 5093-5099.

20. Izzet, G.; Macdonell, A.; Rinfray, C.; Piot, M.; Renaudineau, S.; Derat, E.; Abécassis, B.; Afonso, C.; Proust, A. Metal-Directed Self-Assembly of a Polyoxometalate-Based Molecular Triangle: Using Powerful Analytical Tools to Probe the Chemical Structure of Complex Supramolecular Assemblies. Chem. Eur. J. 2015, 21, 19010-19015.

21. Matt, B.; Renaudineau, S.; Chamoreau, L. M.; Afonso, C.; Izzet, G.; Proust, A. Hybrid Polyoxometalates: Keggin and Dawson Silyl Derivatives as Versatile Platforms. J. Org. Chem. 2011, 76, 3107-3112.

22. Nomiya, K.; Togashi, Y.; Kasahara, Y.; Aoki, S.; Seki, H.; Noguchi, M.; Yoshida, S. Synthesis and Structure of Dawson Polyoxometalate-Based, Multifunctional, InorganicOrganic Hybrid Compounds: Organogermyl Complexes with One Terminal Functional Group and Organosilyl Analogues with Two Terminal Functional Groups. Inorg. Chem. 2011, 50, 9606-9619.

23. Kato, C. N.; Kasahara, Y.; Hayashi, K.; Yamaguchi, A.; Hasegawa, T.; Nomiya, K. Syntheses, characterization, and X-ray crystal structures of mono-lacunary Dawson polyoxometalate-based organosilyl complexes. Eur. J. Inorg. Chem. 2006, 4834-4842.

24. Aoki, S.; Kurashina, T.; Kasahara, Y.; Nishijima, T.; Nomiya, K. Polyoxometalate (POM)-based, multi-functional, inorganic-organic, hybrid compounds: syntheses and molecular structures of silanol- and/or siloxane bond-containing species grafted on mono- and tri-lacunary Keggin POMs. Dalton Trans. 2011, 40, 1243-1253. 
25. Acronyms used for the hybrid POMs: K or D refer to the Keggin or Dawson-type anion respectively, $\mathrm{Si}$ as subscript relates to the primary functionalization and the term in brackets corresponds to the pending reactive function.

26. Duffort, V.; Thouvenot, R.; Afonso, C.; Izzet, G.; Proust, A. Straightforward synthesis of new polyoxometalate-based hybrids exemplified by the covalent bonding of a polypyridyl ligand. Chem. Commun. 2009, 6062-6064.

27. Huo, Z.; Yang, S.; Zang, D.; Farha, R.; Goldmann, M.; Xu, H.; Bonnefont, A.; Matricardi, E.; Izzet, I.; Proust, A.; Ruhlmann, L. Photocurrent Generation from Visible Light Irradiation of Covalent Polyoxometalate-Porphyrin Copolymers. submitted,

28. The attribution of the spectra after the addition of 0.5 and 0.75 equiv. of trans$\left[\mathrm{PdCl}_{2}(\mathrm{MeCN})_{2}\right]$ are not given since such mixtures contain the starting hybrid $\mathbf{K}$ si[pyr] and all its coordination oligomers.

29. Hunter, C. A.; Anderson, H. L. What is Cooperativity? Angew. Chem., Int. Ed. 2009, 48, 7488-7499.

30. Note that the speciation diagram is restricted to the monomer, dimer, triangle and square while other acyclic oligomeric species than the dimer can be present above 0.5 equiv. of Pd(II), as evidenced by the DOSY experiments.

31. Auge, S.; Schmit, P. O.; Crutchfield, C. A.; Islam, M. T.; Harris, D. J.; Durand, E.; Clemancey, M.; Quoineaud, A. A.; Lancelin, J. M.; Prigent, Y.; Taulelle, F.; Delsuc, M. A. NMR Measure of Translational Diffusion and Fractal Dimension. Application to Molecular Mass Measurement. J. Phys. Chem. B 2009, 113, 1914-1918.

32. Floquet, S.; Brun, S.; Lemonnier, J. F.; Henry, M.; Delsuc, M. A.; Prigent, Y.; Cadot, E.; Taulelle, F. Molecular Weights of Cyclic and Hollow Clusters Measured by DOSY NMR Spectroscopy. J. Am. Chem. Soc. 2009, 131, 17254-17259.

33. Bogdan, A. R.; Davies, N. L.; James, K. Comparison of diffusion coefficients for matched pairs of macrocyclic and linear molecules over a drug-like molecular weight range. Org. Biomol. Chem. 2011, 9, 7727-7733.

34. Schmidtchen, F. P. In Supramolecular Chemistry: From Molecules to nanomaterials; John Wiley \& Sons, L., Ed.; 2012.

35. Moschetta, E. G.; Gans, K. M.; Rioux, R. M. Characterization of sites of different thermodynamic affinities on the same metal center via isothermal titration calorimetry. $J$. Catal. 2013, 302, 1-9.

36. Weilandt, T.; Troff, R. W.; Saxell, H.; Rissanen, K.; Schalley, C. A. Metallosupramolecular self-assembly: The case of triangle-square equilibria. Inorg. Chem. 2008, 47, 7588-7598.

37. Mathews, C. J.; Smith, P. J.; Welton, T. N-donor complexes of palladium as catalysts for Suzuki cross-coupling reactions in ionic liquids. J. Mol. Catal. A: Chem. 2004, 214, 27-32. 38. Strohalm, M.; Kavan, D.; Novak, P.; Volny, M.; Havlicek, V. mMass 3: A CrossPlatform Software Environment for Precise Analysis of Mass Spectrometric Data. Anal. Chem. 2010, 82, 4648-4651. 
Table of Contents Graphic

\section{Table of Contents Synopsis}

The metal driven self-assembly of a Keggin-based hybrid leads to the formation of a mixture of molecular triangles and squares. This behavior is different from that of the structural analogue Dawson-based hybrid displaying a higher charge, which only led to the formation of molecular triangles. This studies highlights the decisive effect of the charge of the POMs in their self-assembly processes. 